\title{
Sample Preparation for 3D Characterization of Irradiated Fuel
}

Nuclear Technology

Research and Development

\author{
Prepared for \\ US Department of Energy \\ Advanced Fuels Campaign \\ C. McKinney, J. Harp, and T. Gerczak \\ Oak Ridge National Laboratory \\ April 24, 2020 \\ M3FT-20OR020201072
}





\section{DISCLAIMER}

This information was prepared as an account of work sponsored by an agency of the U.S. Government. Neither the U.S. Government nor any agency thereof, nor any of their employees, makes any warranty,

expressed or implied, or assumes any legal liability or responsibility for the accuracy, completeness, or usefulness, of any information, apparatus, product, or process disclosed, or represents that its use would not infringe privately owned rights. References herein to any specific commercial product, process, or service by trade name, trademark, manufacturer, or otherwise, does not necessarily constitute or imply its endorsement, recommendation, or favoring by the U.S. Government or any agency thereof. The views and opinions of authors expressed herein do not necessarily state or reflect those of the U.S. Government or any agency thereof. 



\section{SUMMARY}

This report presents the approach for preparation of samples for the 3D characterization of nuclear fuel from a radial cross section. In general, 3D characterization is helpful to comprehensively capture the fuel's complex response to irradiation, as $2 \mathrm{D}$ characterization provides less details for observation of certain phenomena. In this work, five blocks and eleven lamella were lifted out of an irradiated segment of a $\mathrm{UO}_{2}$ light water reactor (LWR) fuel pellet. The importance of 3D characterization is presented, followed by the step-by-step process used to remove the blocks. 
This page is intentionally left blank. 


\section{CONTENTS}

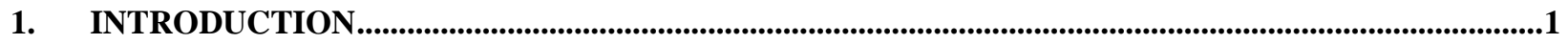

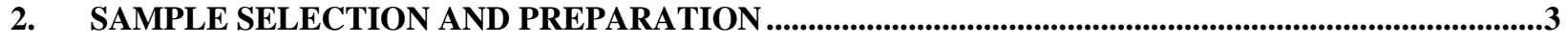

2.1 2D SURFACE ANALYSIS FOR TARGETED LIFT-OUTS .......................................................................

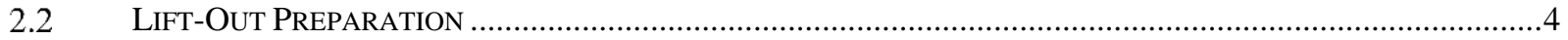

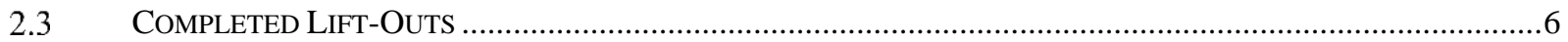

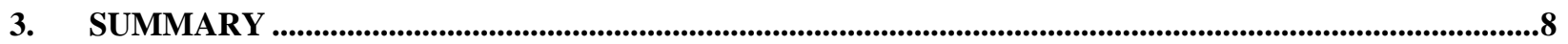

4. APPENDIX A: BLOCK LIFT-OUT RECIPE ..............................................................................................9

5. APPENDIX B: LAMDA LAB AT ORNL LAMELLA LIFT-OUT RECIPE.............................................9

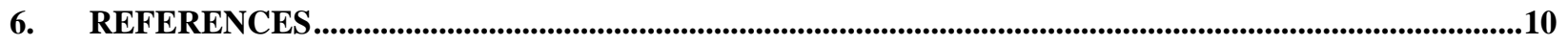


This page is intentionally left blank. 


\section{FIGURES}

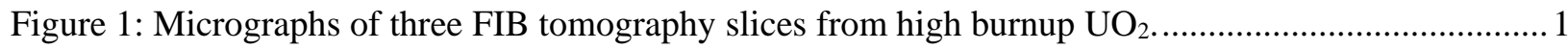

Figure 2. Grain boundary length as a function of radial position for low-angle grain boundaries (LAGBs) and high-angle grain boundaries (HAGBs) (top), EBSD inverse pole figure (IPF) maps overlaid on image quality maps showing the grain orientation of each region (bottom).

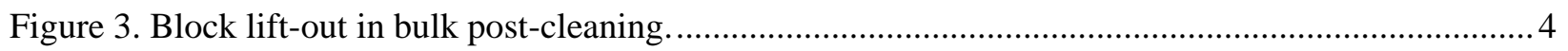

Figure 4. Micrograph showing a successfully undercut block........................................................... 5

Figure 5. Micrographs showing a block being removed from the bulk (left), and a block mounted

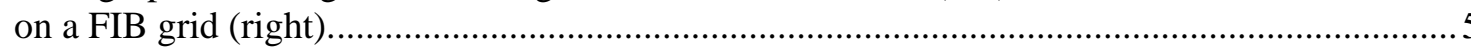

Figure 6. Micrograph of a TEM lamella in bulk (left) and mounted to a grid (right) ............................... 6

Figure 7. Micrograph of the fuel slice after the lift-outs were removed. .................................................. 6 


\section{ACRONYMS}

AFC

Advanced Fuels Campaign

BWR

boiling water reactor

EBSD

electron backscatter diffraction

EDS

energy dispersive X-ray spectroscopy

FIB

focused ion beam

HAGB

high-angle grain boundaries

$\mathrm{HBFF}$

high burnup fuel fragmentation

IPF

inverse pole figure

LAGB

low-angle grain boundaries

LAMDA

Low Activation Materials Development and Analysis

LOCA

loss of cooling accident

LWR

light water reactor

NRC

Nuclear Regulatory Commission

ORNL

Oak Ridge National Laboratory

PIE

post-irradiation examination

PWR

pressurized water reactor

SEM

scanning electron microscope

TEM

transmission electron microscope 


\section{SAMPLE PREPARATION FOR 3D CHARACTERIZATION OF IRRADIATED FUEL}

\section{INTRODUCTION}

Thorough characterization of nuclear fuel is essential when striving to understand its microstructural evolution in response to varying irradiation conditions. A detailed understanding of the microstructural evolution of irradiated fuel can be useful when predicting the fuel's response to off-normal conditions and related phenomena such as high burnup fuel fragmentation (HBFF) and fission gas release [1]. This sort of characterization and the study of complex phenomena like HBFF that are related to fuel performance are an important part of the US Department of Energy Office of Nuclear Energy's Advanced Fuels Campaign (AFC). Multiple characterization techniques are commonly used to perform post-irradiation examination (PIE) analysis on an irradiated fuel sample, but many of these techniques are limited to the 2D surface analysis of the fuel pellet. Although there is a lot of useful information to be gained by analyzing the fuel pellet surface, a 2D analysis provides only an approximation of the nature of the material's features, such as porosity and grain structure. Therefore, it is critical to analyze the 3D structure of the material, as materials exist and respond to conditions in all three dimensions.

Focused ion beam (FIB) tomography has been identified as an optimal technique for characterizing the 3D structure of irradiated fuel. FIB efforts have initially focused on high-burnup commercial $\mathrm{UO}_{2}$ samples. Although FIB tomography is a destructive technique, it provides the necessary spatial resolution needed to study the fuel's microscale features. FIB can be used to analyze larger volumes of irradiated $\mathrm{UO}_{2}$ that would interfere with $\mathrm{x}$-ray tomography techniques [2]. The FIB tomography technique uses a dual-beam FIB/scanning electron microscope (SEM) to collect stacks of images as it sequentially mills through the material. An image of the cube's surface is obtained using the SEM's electron beam. Then the FIB mills away a specific amount of material, and the SEM obtains another image. This process is repeated until the entire targeted volume of material has been milled away. Figure 1 shows three slices from FIB tomography of high burnup $\mathrm{UO}_{2}$ to illustrate the process. These images are reassembled to provide a 3D microstructural image of the material. This technique can be performed with simultaneous electron backscatter diffraction (EBSD)/energy dispersive x-ray spectroscopy (EDS) to collect local crystallographic orientation information and microchemical information, resulting in a comprehensive reconstruction of the material's microstructure. To prevent the data from being obscured by shadowing or redeposition, this technique is most effective when the volumes of material targeted for analysis are removed from the bulk. The process of selecting areas of focus and performing bulk lift-outs is described herein. Once the blocks are removed, they can be analyzed in an automated process that sequentially progresses through the microstructure so that the 3D microstructure can be reconstructed using postprocessing image analysis software like performed by McKinney and Teague [1,3].
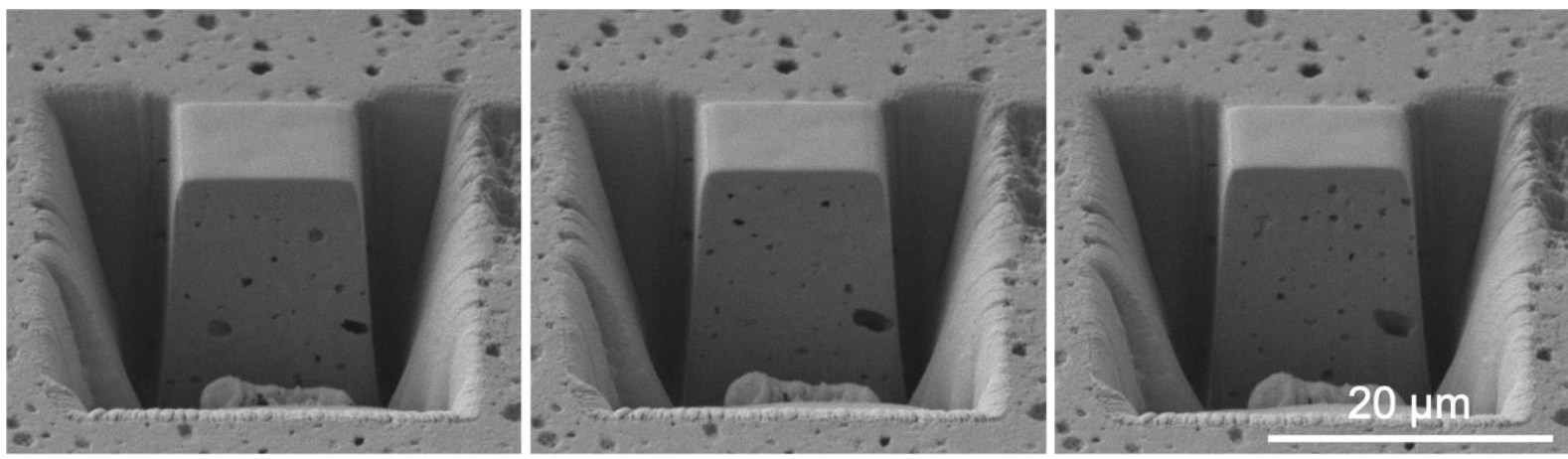

Figure 1: Micrographs of three FIB tomography slices from high burnup $\mathrm{UO}_{2}$. 
In this work, blocks for 3D characterization were targeted and lifted out of a sample of $\mathrm{UO}_{2}$ that had been irradiated in the commercial Limerick boiling water reactor (BWR) [4]. Studying light water reactor (LWR) $\mathrm{UO}_{2}$ fuel radial cross sections presents an interesting opportunity to analyze $\mathrm{UO}_{2}$ regions that experienced local variations in temperature and different burnups as well. In $\mathrm{LWR} \mathrm{UO}_{2},{ }^{239} \mathrm{Pu}$ is generated on the periphery of the pellet due to resonance neutron absorption, which allows the rims of the pellets to reach much higher burnups than their centers [5]. By conducting a radial examination of the microstructure, the evolution of the microstructure with respect to varying temperatures and burnups can be discerned. Because the 3D examination is time consuming and volume limited, locations of the bulk lift-outs must be judiciously selected. To ensure systematic 3D examination of the microstructure, the blocks were targeted according to the radial evolution of the grain structure shown in the larger length scale $2 \mathrm{D}$ analysis of the fuel radius. This was accomplished by periodically collecting EBSD maps across the radius of the pellet so that regions could be selected for the targeted lift-outs.

The phenomenon of $\mathrm{HBFF}$ in light water reactor $\mathrm{UO}_{2}$ has received increasing attention over the years as the average discharge burnup of assemblies from nuclear power plants have begun to rise. There is now economic incentive for many nuclear power plants to extend their burnups beyond the current Nuclear Regulatory Commission (NRC) limit of $62 \mathrm{GWd} / \mathrm{MTU}$ average rod burnup [6]. A challenge for extending burnup is recent loss of cooling accident (LOCA) testing results that demonstrate the threshold for fine fuel fragmentation or pulverization during a LOCA event can be closer to this burnup than previously believed [7]. These results stimulated further work that showed the severity of HBFF is dependent on the local temperature and burnup of $\mathrm{UO}_{2}$ at the time a LOCA event begins [8]. Given this research on the current understanding of HBFF, it appears that there are operation condition restrictions that can be applied to safely operate fuel assemblies with fuel peak average rod burnup above 62 GWd/MTU. However, the current interpretation does not provide a phenomenological basis for HBFF. The onset of HBFF is understood only through integral engineering properties of burnup and temperature (or linear power). Understanding fuel performance in this way represents a proven but slow, expensive approach to nuclear fuel licensing [9]. Accelerated fuel qualification may be achieved by combining separate effects testing, modeling and simulation and targeted integral tests. Part of the understanding necessary to accelerate qualification in microstructural characterization and understanding how fuel microstructures evolve through different irradiation histories. Different irradiation histories can create different microstructures in fuels like $\mathrm{UO}_{2}$. Unfortunately, little to no microstructural examination was performed on the fuel used to create the current understanding of HBFF. However, it is clear that the susceptibility of $\mathrm{UO}_{2}$ to $\mathrm{HBFF}$ is related to operating power history (which controls local temperature) and this dramatically impacts the local microstructure of $\mathrm{UO}_{2}$ at high burnup. Therefore, careful and thorough microstructural characterization like the techniques described in this work is critical to the understanding of $\mathrm{UO}_{2}$ fuel performance for a variety of different irradiation histories.

Creating characterization and simulation techniques along with evaluation methodologies to better understand $\mathrm{UO}_{2}$ behavior under irradiation in light water reactors has become a key activity in the AFC. By conducting a systematic investigation of the 3D microstructure that includes crystallographic and chemical information in high burnup $\mathrm{UO}_{2}$, a linkage between the local comprehensive microstructure and irradiation history can be determined. Once this relationship is understood, modelling can be validated by these experiments and then utilized to predict conditions that might prompt HBFF during off-normal accident scenarios such as a LOCA. A deeper understanding of the conditions and microstructures that lead to fuel fragmentation is essential when aiming to understand a fuel's response to an accident and potentially develop mitigation strategies. 


\section{SAMPLE SELECTION AND PREPARATION}

\subsection{D Surface Analysis for Targeted Lift-Outs}

A systematic investigation of the grain morphology across the radius of a fuel pellet from the Limerick BWR sample [4] was conducted to locate regions of interest for 3D characterization. The grain characteristics were used to partition the fuel into regions, similar to what was previously performed on a fuel sample from the H. B. Robinson pressurized water reactor (PWR) and described by Gerczak [10]. Figure 2 shows how the different regions of fuel were defined based on variations in their grain boundary characteristics. It is important to note that this figure was obtained prior to final data refinement, but it includes sufficient information to allow for differentiating fuel regions. The different regions representing interesting transitions in fuel evolution were targeted for analysis of the mechanisms driving fuel evolution. Using Figure 2 as a guide, five areas of interest were targeted for lift-outs, including one area from each region, and an additional area at $\mathrm{r} / \mathrm{r}_{0}=0.33$. This additional area was chosen so that the switch from low-angle grain boundary (LAGB) to high-angle grain boundary (HAGB) dominance could be investigated. This factor was not previously seen in Gerczak's investigation of the H. B. Robinson fuel sample. At this time, the shift in grain boundary type dominance is still under investigation, but this behavior is expected to play a role in understanding $\mathrm{UO}_{2}$ behavior under LWR irradiation conditions.
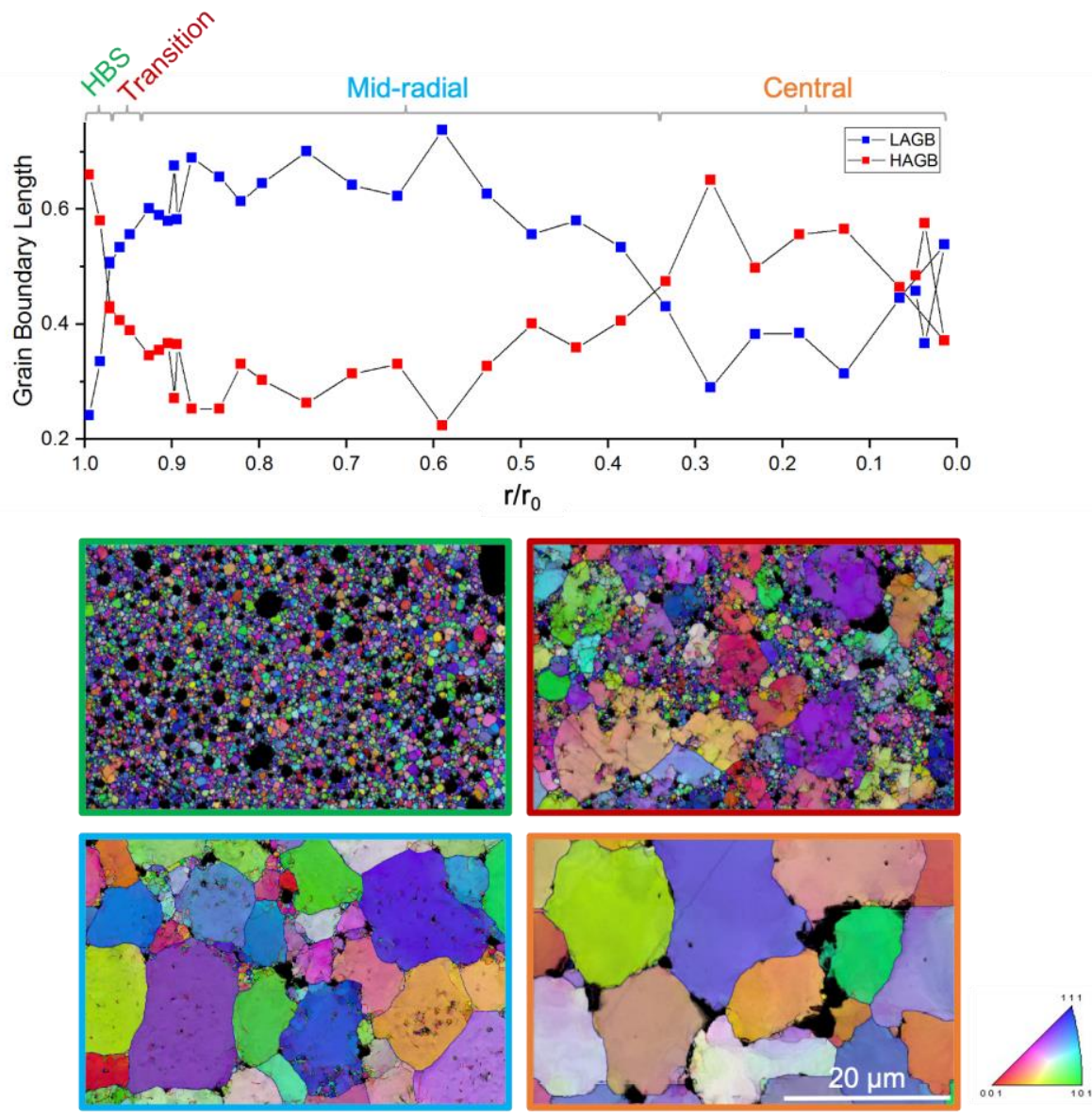

Figure 2. Grain boundary length as a function of radial position for low-angle grain boundaries (LAGBs) and high-angle grain boundaries (HAGBs) (top), EBSD inverse pole figure (IPF) maps overlaid on image quality maps showing the grain orientation of each region (bottom). 


\subsection{Lift-Out Preparation}

Based on the time needed to perform the block analysis and to ensure that each block would include multiple grains, a volume of $25 \mu \mathrm{m} \times 25 \mu \mathrm{m} \times 25 \mu \mathrm{m}$ was targeted for all block lift-outs. Due to the high dose of the fuel, the shielded FEI Quanta dual-beam FIB/SEM in the Oak Ridge National Laboratory (ORNL) Low Activation Materials Development and Analysis (LAMDA) Laboratory was used to remove the blocks. Preparation of the blocks began with the deposition of platinum (Pt) on the surface of the fuel sample to protect it from ion beam damage during the lift-out process. A layer of Pt $3 \mu \mathrm{m}$ thick was deposited over an area of approximately $25 \mu \mathrm{m} \times 25 \mu \mathrm{m}$. The Pt layer had to be thick enough to protect the sample from the high ion beam energies used to mill such large volumes of material for block removal. After Pt deposition, large trenches were milled on three sides of the block using a $50 \mathrm{nA}$ ion beam to increase the material removal rate. The third large trench was milled to prevent issues associated with redeposition of milled material and to allow for visualization of the undercut prior to removal. On the fourth side of the block, a small rectangular trench was also milled using a $50 \mathrm{nA}$ beam. The four sides of the block were then cleaned using a $30 \mathrm{nA}$ beam. A rim of fuel not covered by Pt approximately 2-3 $\mu \mathrm{m}$ thick was left on the block to protect it during storage. Prior to 3D characterization, this rim will be cleaned off using a low $7 \mathrm{nA}$ ion beam. Figure 3 shows a block after cleaning with a protective rim and Pt cap.

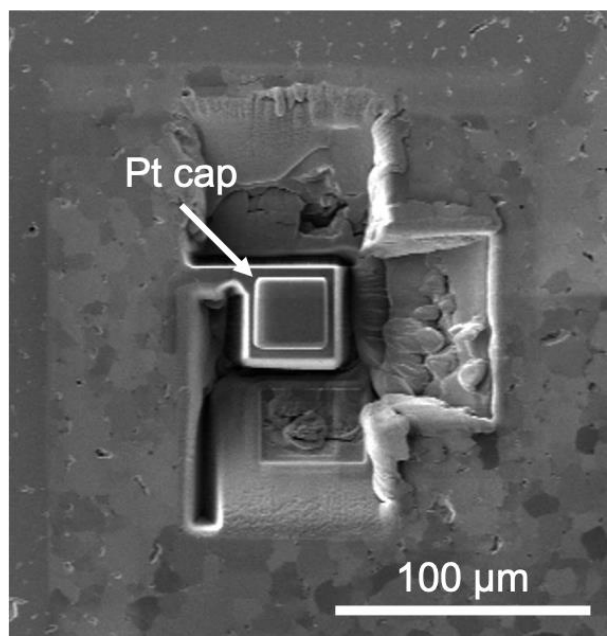

Figure 3. Block lift-out in bulk post-cleaning.

After the block was cleaned, it was undercut to facilitate removal. The microscope stage was tilted from the standard $52^{\circ}$ angle used for milling down to a $7^{\circ}$ tilt, which allowed for a $45^{\circ}$ undercut to be milled. The front and back sides of the block were undercut with a $15 \mathrm{nA}$ beam for approximately 30 minutes each. After the second undercut had been completed, the first undercut was milled again with a $7 \mathrm{nA}$ beam for 10 minutes to remove any redeposition that had accumulated when milling the second undercut. To check the completion of the undercut, the stage was rotated $90^{\circ}$ and tilted to $30^{\circ}$ so that the undercut could be visualized from the third trench on the side of the block, as shown in Figure 4. 


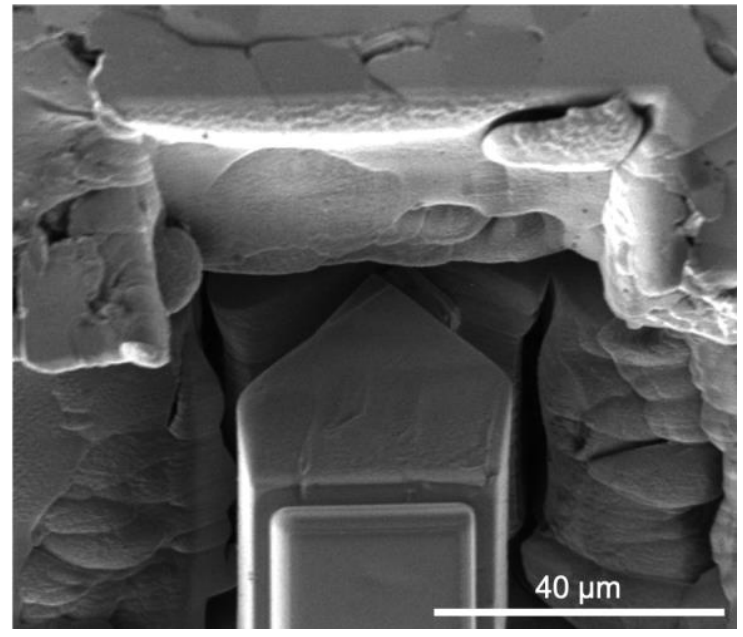

Figure 4. Micrograph showing a successfully undercut block.

Once the block was successfully undercut, it was removed from the bulk using the OmniProbe, as shown in the left image of Figure 5. Both the grid and the bottom of the block required shaping before being welded to the grid. Due to redeposition, the bottom of the block was not flat; this would affect the quality of the weld to the grid. Therefore, the bottom of the block was cleaned with a $7 \mathrm{nA}$ beam so that it would align flush to the grid and allow for a strong weld. The chevron grid post was chosen for the mounting location to provide added protection for the block during storage; however, it required shaping to align flush with the edge of the grid. The grid was milled with a $15 \mathrm{nA}$ beam until the surface was suitably flat for mounting. After the grid and block had been shaped, the block was welded to the grid using a $2.5 \mu \mathrm{m}$ layer of Pt. The block was then cut free from the OmniProbe, and the stage was rotated $180^{\circ}$ so that the other side of the block could be welded with another $2.5 \mu \mathrm{m}$ layer of Pt. A block that was removed from the bulk and mounted to a chevron grid post is pictured in Figure 5. The process for removing the blocks is summarized in Appendix A.
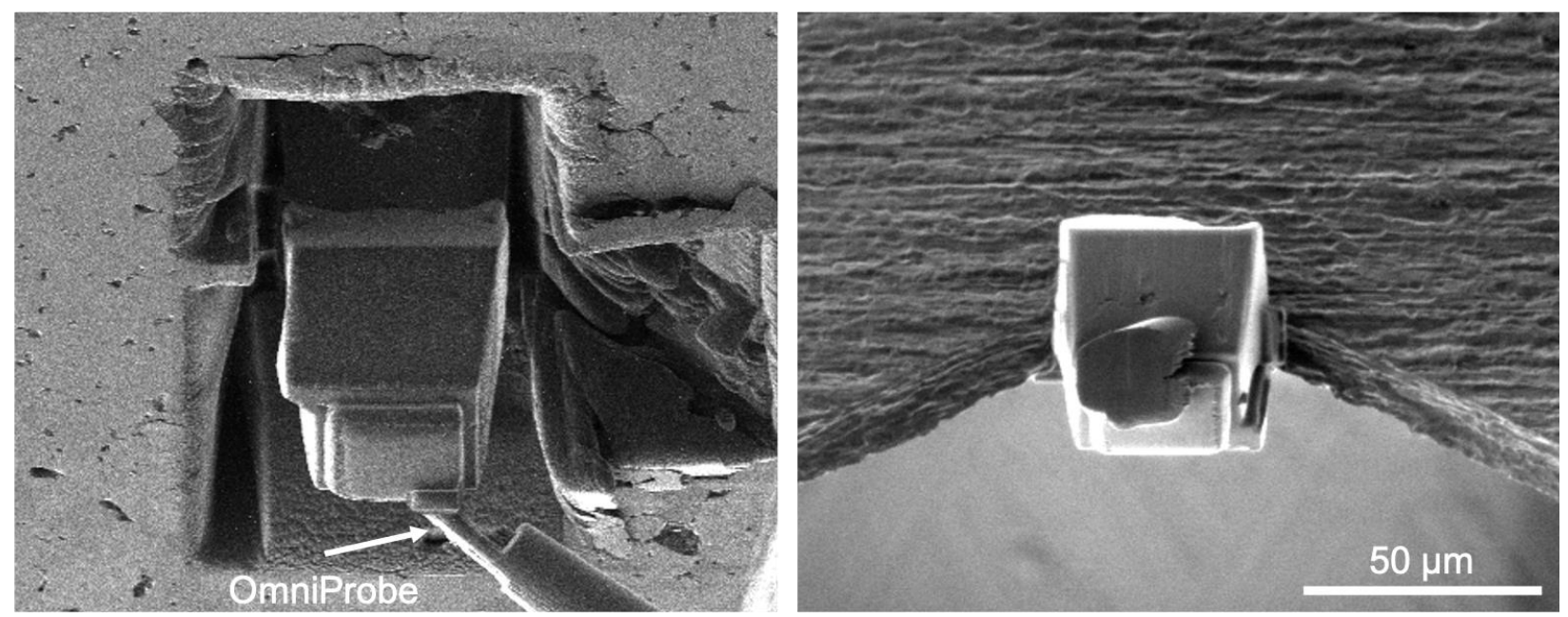

Figure 5. Micrographs showing a block being removed from the bulk (left), and a block mounted on a FIB grid (right).

For each block location, it was decided that two lamella for transmission electron microscopy (TEM) analysis would be lifted out to complement the 2D and 3D characterizations performed on the sample. 
The standard lift-out procedure used in the LAMDA Laboratory at ORNL was used to remove all lamellas. The LAMDA lift-out recipe can be found in Appendix B. Two large trenches were milled with a $15 \mathrm{nA}$ beam, and two cleaning steps were performed with 7 and $5 \mathrm{nA}$ beams, followed by undercutting and removal using the OmniProbe. In the left image of Figure 6, a lamella is shown with respect to the trench of a previous block lift-out for scale reference. An example of a completed lamella lift-out that has been removed from the bulk and mounted to a grid is shown in the right-hand image in Figure 6.
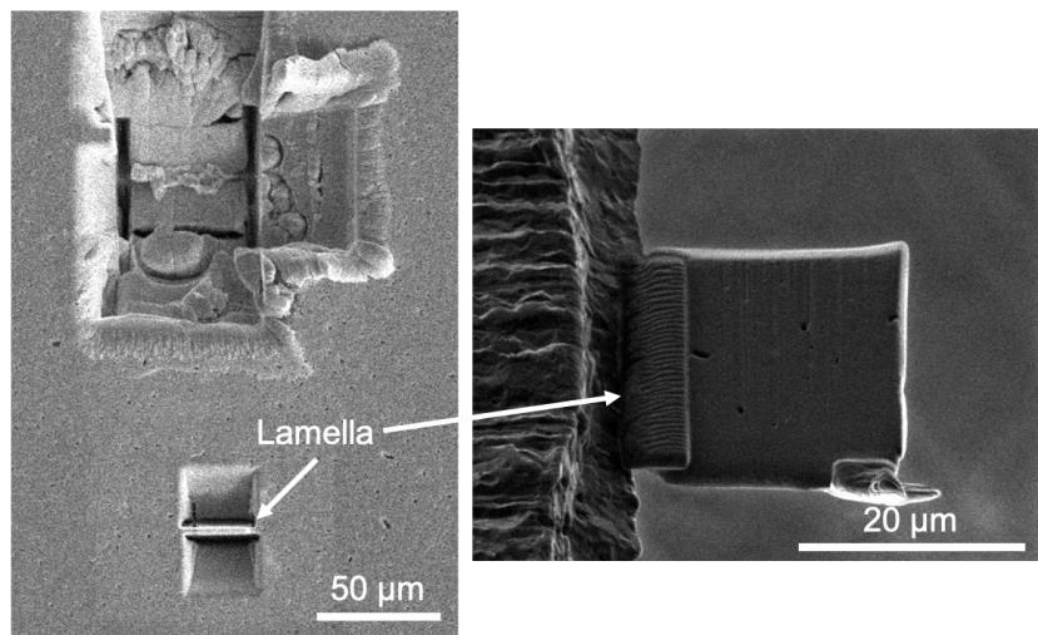

Figure 6. Micrograph of a TEM lamella in bulk (left) and mounted to a grid (right).

\subsection{Completed Lift-Outs}

Using the preparation methods described above, five block lift-outs and eleven lamella lift-outs were successfully removed from the Limerick BWR $\mathrm{UO}_{2}$ fuel segment. In Figure 7, an overview micrograph of the fuel segment can be seen after all lift-outs were removed. One region had an extra lamella removed due to damage that occurred during the thinning process of one of the previous two lamella. There is also an additional block closest to the center of the fuel pellet that had to remain in the sample because of cracking across the block during sample preparation. It was possible that the block would fall apart if removal had been attempted, so it was left in the bulk of the fuel to minimize the risk of unnecessary contamination from handling. The cracking was assumed to be the result of residual stress in the material from the surface crack across the fuel segment closest to the block. A list of the lift-outs, both removed and in bulk, is given in Table 1.

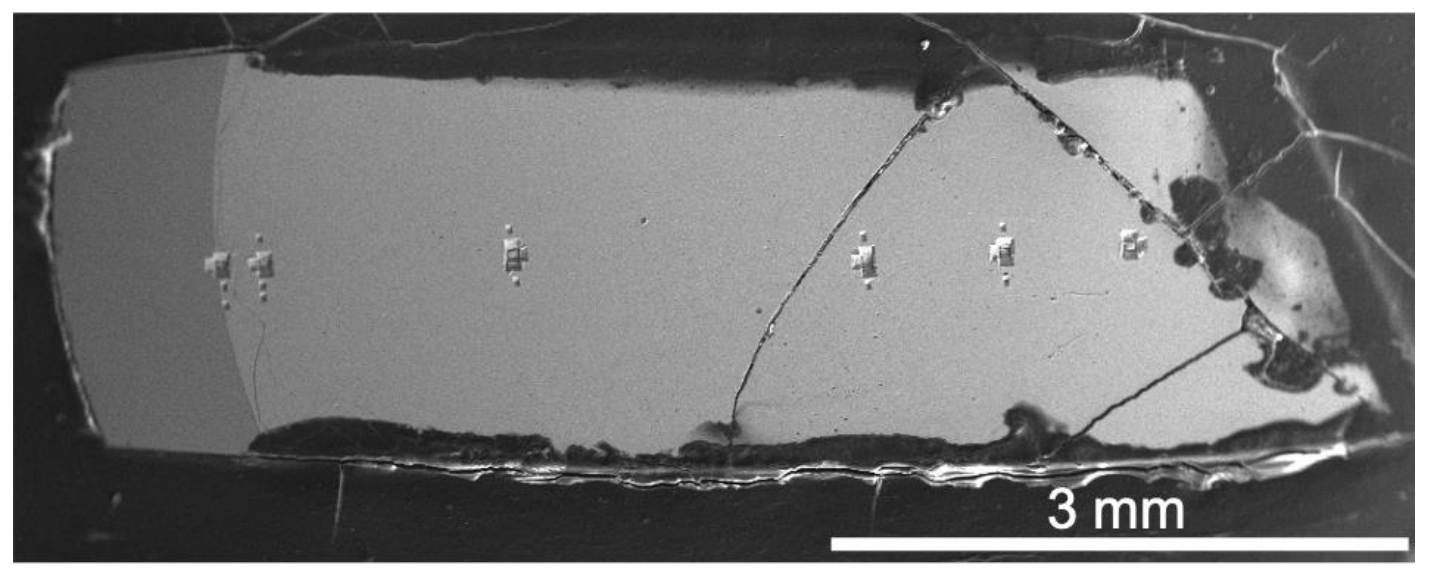

Figure 7. Micrograph of the fuel slice after the lift-outs were removed. 
Table 1. Lift-Outs from Each Region

\begin{tabular}{|lcccc|}
\hline Region & $\mathrm{r} / \mathrm{r}_{0}$ & $\begin{array}{c}\text { Number of } \\
\text { Blocks }\end{array}$ & $\begin{array}{c}\text { Number of } \\
\text { Lamella }\end{array}$ & Removed \\
\hline HBS & 0.99 & 1 & 2 & Yes \\
Transition & 0.96 & 1 & 3 & Yes \\
Mid-radial & 0.70 & 1 & 2 & Yes \\
Mid-radial & 0.33 & 1 & 2 & Yes \\
Central & 0.18 & 1 & 2 & Yes \\
Central & 0.03 & 1 & 0 & No* \\
\hline \multicolumn{4}{r}{} \\
\end{tabular}




\section{Sample Preparation for 3D Characterization of Irradiated Fuel}

\section{SUMMARY}

A process for strategically targeting regions in $\mathrm{LWR} \mathrm{UO}_{2}$ fuel segments for $3 \mathrm{D}$ analysis was defined and executed. The effort resulted in a standard recipe for $3 \mathrm{D}$ block fabrication and lift-out from $\mathrm{UO}_{2}$. In this

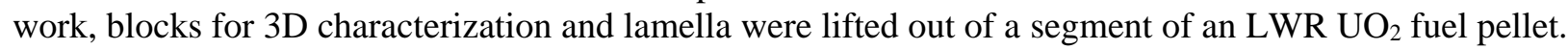
Five blocks and eleven lamella were successfully removed and mounted to grids for further characterization. The lessons learned from this work encompass the steps of the block lift-out process, including the particular importance of the third large trench in reducing redeposition and allowing for visualization of the undercut. These blocks will be characterized using FIB tomography with simultaneous EBSD/EDS so that the local comprehensive 3D microstructure can be rebuilt using postprocessing image analysis software. The reconstructed 3D microstructures will be utilized to determine a relationship between local microstructure and burnup. This relationship can be used with modelling to determine conditions that might promote fuel fragmentation, which is essential when working to support AFC's mission to support extended burnup for current light water reactors and develop future accident tolerant fuels. 


\section{APPENDIX A: BLOCK LIFT-OUT RECIPE}

\begin{tabular}{|c|c|c|c|c|c|c|c|}
\hline \multicolumn{8}{|c|}{ Block Lift Out } \\
\hline Steps & Stage Tilt & Beam Energy & Beam Current & Est. Cut shape (IIw]h) & Cut type & Milling End line & Time (min) \\
\hline \multicolumn{8}{|c|}{ SEM image : 30kV, 0.81nA, FIB image : 30kV, 10pA, WD $14.9 \mathrm{~mm}$ (Quanta): $10 \mathrm{~mm}$ (Versa) -> Find Eucentric @ $0^{\circ} / 30^{\circ} / 52^{\circ}$ (Use manual Z-stage movements) ->Insert Pt dep. nozzle (Warm up) } \\
\hline \begin{tabular}{|l|l|l} 
Pt deposition & \\
\end{tabular} & $52^{\circ}$ & $30 \mathrm{kV}$ & $0.5 \mathrm{nA}$ & $25 \times 25 \times 3 \mu \mathrm{m}(15 \mu \mathrm{m}$ gap between two dep.) & rect. deposit. & & 120 \\
\hline \multicolumn{8}{|c|}{ Withdraw Pt dep. nozzle (Cool down) } \\
\hline Hog cut & $52^{\circ}$ & $30 \mathrm{kV}$ & $50 \mathrm{nA}$ & $75 \times 50 \times 50 \mu \mathrm{m}$ (mult-scan, serial), $\mathrm{Si}$ & regular cross & $15 \mu \mathrm{m}$ From Pt & $60(180)$ \\
\hline Hog cut & $52^{\circ}$ & $30 \mathrm{kV}$ & $50 \mathrm{nA}$ & $15 \times 35 \times 30 \mu \mathrm{m}, \mathrm{Si}$ & rectangle & $15 \mu \mathrm{m}$ From Pt & 30 \\
\hline Skirt shaping & $52^{\circ}$ & $30 \mathrm{kV}$ & $30 \mathrm{nA}$ & $\mathrm{I} \times \mathrm{w}$ cover redep. $\mathrm{h}=10 \mu \mathrm{m}$ & cleaning cross & $5 \mu \mathrm{m}$ From Pt & $22.5(90)$ \\
\hline \multicolumn{8}{|c|}{ Tilt to $7^{\circ}$} \\
\hline Undercut (U-cut) & $7^{\circ}$ & $30 \mathrm{kV}$ & $15 \mathrm{nA}$ & U-cut around block, $\mathrm{h}=25 \mu \mathrm{m}$ (parallel) & rectangle & SP. $w=35 h=28$ & 30 \\
\hline \multicolumn{8}{|c|}{ Compucentric rotation FIB $180^{\circ}$} \\
\hline Undercut (U-cut) & $7^{\circ}$ & $30 \mathrm{kV}$ & $15 \mathrm{nA}$ & U-cut around block, $\mathrm{h}=25 \mu \mathrm{m}$ (parallel) & rectangle & SP. $w=35 h=28$ & 30 \\
\hline \multicolumn{8}{|c|}{ Compucentric rotation FIB $180^{\circ}$} \\
\hline Undercut (U-cut) & $7^{\circ}$ & $30 \mathrm{kV}$ & $7 \mathrm{nA}$ & U-cut around block, $\mathrm{h}=25 \mu \mathrm{m}$ (parallel) & rectangle & SP. $w=35 \mathrm{~h}=28$ & 10 \\
\hline Omniprobe approach & $0^{\circ}$ & $30 \mathrm{kV}$ & $10 \mathrm{pA}$ & imaging & & & \\
\hline \multicolumn{8}{|c|}{ ilt to $0^{\circ}$, Min. Mag, Beam shift 0, PT nozzle in (warm up), Omniprobe in (Z(in), $X(a w a y), Y(d o w n), Y Z($ down \& in, $5 K$ SEM live image), $X Y Z$ (approach, 12K FIB live image, estimate height with focus(SE) \& shadow(ION)): parking $\rightarrow$ eucentric height $\rightarrow X, Y \rightarrow Z Z$} \\
\hline \begin{tabular}{|l|} 
Omniprobe weld \\
\end{tabular} & $0^{\circ}$ & $30 \mathrm{kV}$ & $0.5 \mathrm{nA}$ & patch $\mathrm{h}=3 \mu \mathrm{m}$ & rect. deposit. & SP. top edge & 12 \\
\hline Free cut & $0^{\circ}$ & $30 \mathrm{kV}$ & $7 \mathrm{nA}$ & $\mathrm{h}=10 \mu \mathrm{m}$ & rectangle & & 6 \\
\hline \multicolumn{8}{|c|}{ Work block out with Omniprobe controls } \\
\hline \multirow{2}{*}{\multicolumn{8}{|c|}{$\begin{array}{c}\text { hniprobe Parking (Y Up (Lift) to the limit }->\text { Z Out (Out), Quanta) or press parking (Versa)-> Withdraw Omniprobe }->\text { Withdraw Pt dep. Nozzle : eucentric height }->\text { Parking } \\
\text { Mount Block to Grid }\end{array}$}} \\
\hline & & & & & & & \\
\hline \multicolumn{8}{|c|}{ Beam shift 0, Find Eucentric @ $0^{\circ} / 30^{\circ} / 52^{\circ}$ (chevron center, $\mathrm{xT}$ align for horizontal)-> Min. Mag. $>>$ Insert Pt dep. needle-> Insert Omniprobe $->$ Power on } \\
\hline Omniprobe approach & $0^{\circ}$ & $30 \mathrm{kV}$ & $10 \mathrm{pA}$ & imaging & & & \\
\hline Block Shaping & $0^{\circ}$ & $30 \mathrm{kV}$ & $7 \mathrm{nA}$ & Cover uneven bottom, $\mathrm{Si}$ & cleaning cross & & 5 \\
\hline Grid Shaping & $0^{\circ}$ & $30 \mathrm{kV}$ & $15 \mathrm{nA}$ & rect with $\mid x w$ to fit block flush $h=20 \mu \mathrm{m}, \mathrm{Si}$ & rectangle & & 25 \\
\hline Grid weld & $0^{\circ}$ & $30 \mathrm{kV}$ & $0.5 \mathrm{nA}$ & patch $\mathrm{h}=2.5 \mu \mathrm{m}$ & rect. deposit. & SP. edge & 60 \\
\hline Free cut & $0^{\circ}$ & $30 \mathrm{kV}$ & $7 \mathrm{nA}$ & $\mathrm{h}=10 \mu \mathrm{m}$ & rectangle & & 10 \\
\hline \multicolumn{8}{|c|}{ Compucentric rotation FIB $180^{\circ}$} \\
\hline Grid weld & $0^{\circ}$ & $30 \mathrm{kV}$ & $0.5 \mathrm{nA}$ & patch $\mathrm{h}=2.5 \mu \mathrm{m}$ & rect. deposit. & SP. edge & 60 \\
\hline
\end{tabular}

Note that the time used for each step is the time period for which each process was allowed to run. The software predicted longer times, but the time used was found to be sufficient due to the faster milling rate of the $\mathrm{UO}_{2}$ compared to the standard times for silicon that the software uses to predict milling times. It should also be noted that milling times will vary slightly by region, depending on the local microstructure.

\section{APPENDIX B: LAMDA LAB AT ORNL LAMELLA LIFT-OUT RECIPE}

\begin{tabular}{|c|c|c|c|c|c|c|c|c|}
\hline \multicolumn{9}{|c|}{ Lift-out } \\
\hline Steps & Stage Tilt & Beam Energy & Beam Current & Est. Cut shape (IIw [h) & Cut type & Milling End line & Target thick. & Time (min) \\
\hline \multicolumn{9}{|c|}{ SEM image : 30kV, 0.81nA, FIB image : 30kV, 10pA, WD $14.9 \mathrm{~mm}$ (Quanta):10mm (Versa) -> Find Eucentric @ @ 0\%/30\% $/ 52^{\circ}$ (Use manualZ-stage movements) - > Insert Pt dep. nozzle (Warm up) } \\
\hline Pt deposition & $52^{\circ}$ & $30 \mathrm{kV}$ & $0.5 \mathrm{nA}(\mathrm{Q}): 100 \mathrm{pAN})$ & $20 \times 2 \times 3.25 \mu \mathrm{m}(15 \mu \mathrm{m}$ gap between two dep.) & rect. deposit. & & $2.0 \mu \mathrm{m}$ & \\
\hline \multicolumn{9}{|c|}{ Withdraw Pt dep. nozzle (Cool down) } \\
\hline Hog cut & $52^{\circ}$ & $30 \mathrm{kV}$ & $15 \mathrm{nA}$ & $28 \times 20 \times 20 \mu \mathrm{m}$ (mult-scan, serial), Si(Q):Si ccs Fast (V) & regular cross & $2 \mu \mathrm{m}$ From PT & $4.0 \mu \mathrm{m}$ & $20(40)$ \\
\hline Skirt shaping & $52^{\circ}+/-2.0^{\circ}$ & $30 \mathrm{kV}$ & $7 \mathrm{nA}$ & $28 \times 2 \times 3 \mu \mathrm{m}$ & cleaning cross & SP. edge & $3.0 \mu \mathrm{m}$ & $2.5(5)$ \\
\hline Skirt shaping & $52^{\circ}+1-2.0^{\circ}$ & $30 \mathrm{kV}$ & $5 \mathrm{nA}$ & $28 \times 2 \times 3 \mu \mathrm{m}$ & cleaning cross & SP. edge & $<2.0 \mu \mathrm{m}$ & $3.5(7)$ \\
\hline \multicolumn{9}{|c|}{ Tilt to $7^{\circ}$} \\
\hline Undercut (U-cut) & $7^{\circ}$ & $30 \mathrm{kV}$ & $3 \mathrm{nA}$ & \begin{tabular}{|l}
$22 \times 2 \times 3 \mu \mathrm{m}$ (parallel) \\
$2 \times 15(10$ with tilt) $\times 3 \mu \mathrm{m}$
\end{tabular} & rectangle & SP. 18X13 edge & & \\
\hline \multicolumn{9}{|c|}{ Compucentric rotation FIB $180^{\circ}$} \\
\hline Undercut (U-cut) & $7^{\circ}$ & $30 \mathrm{kV}$ & $3 \mathrm{nA}$ & $\begin{array}{l}22 \times 2 \times 3 \mu \mathrm{m} \text { (parallel) } \\
2 \times 15(10 \text { with tilt) } \times 3 \mu \mathrm{m}\end{array}$ & rectangle & SP. $18 \times 13$ edge & & 9 \\
\hline \multicolumn{9}{|c|}{ Tilt to $25^{\circ}$ to verify undercut, Compucentric rotation back to 0} \\
\hline Omniprobe approach & $0^{\circ}$ & $30 \mathrm{kV}$ & $10 \mathrm{pA}$ & limaging & & & & \\
\hline \multirow{2}{*}{\multicolumn{9}{|c|}{ 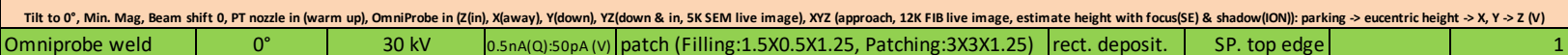 }} \\
\hline & & & & & & & & \\
\hline Free cut & $0^{\circ}$ & $30 \mathrm{kV}$ & $3 \mathrm{nA}$ & $2 \times B \times 3 \mu \mathrm{m}$ & rectangle & & & \\
\hline
\end{tabular}

Omniprobe Parking (Y Up (Lift) to the limit -> Z Out (Out), Quanta) or press parking (Versa)-> Withdraw Omniprobe ->Withdraw Pt dep. Nozzle : eucentric height -> Parking (V) 


\section{REFERENCES}

[1] C. McKinney, R. Seibert, G. Helmreich, A. Aitkaliyeva and K. Terrani, "Three-dimensional bubble reconstruction in high burnup UO2," Journal of Nuclear Materials, vol. 532, 2020.

[2] C. Silva, L. Snead, J. Hunn, E. Specht, K. Terrani and Y. Katoh, "Application of X-ray microcomputed tomography in the characterization of irradiated nuclear fuel and material specimens," Journal of Microscopy, vol. 260, no. 2, pp. 163-174, 2015.

[3] M. Teague, B. Gorman, B. Miller and J. King, "EBSD and TEM characterization of high burn-up mixed oxide fuel," Journal of Nuclear Materials, vol. 444, no. 1-3, pp. 475-480, 2014.

[4] H. Tsai and M. Billone, "Characterization of high-burnup PWR and BWR rods, and PWR rods after extended dry-cask storage," in 30th Nuclear Safety Research Conference, Washington, D.C., U.S.A., 2003.

[5] C. Lee and Y. Jung, "An attempt to explain the high burnup structure formation mechanism in UO2 fuel," Journal of Nuclear Materials, vol. 279, no. 2-3, pp. 207-215, 2000.

[6] V. Jain, G. Cragnolino and L. Howard, "A review report on high burnup spent nuclear fuel - disposal issues," U.S. Nuclear Regulatory Commission, San Antonio, TX, U.S.A., 2004.

[7] M. Flanagan and P. Askeljung, "Post-test examination results from integral, high-burnup, fueled LOCA tests at Studsyik Nuclear Laboratory," U.S. Nuclear Regulatory Commission, Washington, D.C., U.S.A., 2013.

[8] J. Turnbull, S. Yagnik, M. Hirai, D. Staicu and C. Walker, "An assesment of the fuel pulverization threshold during LOCA-type temperature transients," Nuclear Science and Engineering, vol. 179, no. 4, pp. 477-485, 2015.

[9] D. Crawford, D. Porter, S. Hayes, M. Meyer, D. Petti and K. Pasamehmetoglu, "An approach to fuel development and qualification," Journal of Nuclear Materials, vol. 371, no. 1-3, pp. 232-242, 2007.

[10] T. Gerczak, C. Parish, P. Edmondson, C. Baldwin and K. Terrani, "Restructuring in high bunrup UO2 studied using modern electron microscopy," Journal of Nuclear Materials, vol. 509, pp. 245-259, 2018. 